\title{
Application of GATA-3 gene marker in the detection of hematologic disorders in children
}

\author{
FENGHUA WANG $^{1}$ and LILI BIE ${ }^{2}$ \\ ${ }^{1}$ Institute of Physical Education, Xinjiang Normal University, Urumqi, Xinjiang 830054; ${ }^{2}$ Department of Blood \\ Component Preparation, Henan Red Cross Blood Center, Zhengzhou, Henan 450000, P.R. China
}

Received July 7, 2017; Accepted November 16, 2017

DOI: 10.3892/etm.2017.5614

\begin{abstract}
The aim of the present study was to investigate the use of GATA-3 markers in the detection of hematologic disorders in children. In total, 35 pediatric patients diagnosed with blood disease and treated in Henan Red Cross Blood Center from January 2014 to June 2015 were selected for the observation group. Another 32 healthy children were selected for the control group. The differences in the GATA-3 mRNA expression levels between the control and observation groups were detected via reverse transcription-quantitative polymerase chain reaction (RT-qPCR). The differences in the GATA-3 protein expression levels were detected via enzyme-linked immunosorbent assay (ELISA) and western blot analysis. Compared with those in the healthy children, the mRNA expression levels of GATA-3 in patients with hematologic malignancies, acute lymphoblastic leukemia, myeloproliferative disorder, acute non-lymphocytic leukemia or thrombocytopenic purpura were significantly higher, and there were statistically significant differences between the groups $(\mathrm{P}<0.05)$. The results of ELISA showed that the GATA-3 protein expression levels in patients with hematologic malignancies $(241.3 \pm 42.6 \mu \mathrm{g} / \mathrm{l})$, acute lymphoblastic leukemia $(196.3 \pm 21.6 \mu \mathrm{g} / 1)$, myeloproliferative disorder $(284.2 \pm 45.1 \mu \mathrm{g} / \mathrm{l})$, acute non-lymphocytic leukemia $(269.3 \pm 31.4 \mu \mathrm{g} / \mathrm{l})$ or thrombocytopenic purpura $(272.1 \pm 39.1 \mu \mathrm{g} / \mathrm{l})$ were significantly higher than those in healthy subjects $(69.3 \pm 15.2 \mu \mathrm{g} / \mathrm{l})$. The results of western blot analysis were consistent with those of ELISA. Based on our results, the expression levels of GATA-3 in healthy children and pediatric patients with blood diseases exhibit significant differences, and can be used as important markers for the clinical diagnosis of blood diseases in children.
\end{abstract}

Correspondence to: Dr Fenghua Wang, Institute of Physical Education, Xinjiang Normal University, 102 Xinyi Road, Urumqi, Xinjiang 830054, P.R. China

E-mail: fenghua_wang01@163.com

Key words: GATA-3, patients with, patients with acute lymphoblastic leukemia, patients with myeloproliferative disorder, acute non-lymphocytic leukemia, thrombocytopenic purpura

\section{Introduction}

Statistical data indiate that the number of patients suffering from different blood diseases worldwide has reached more than 36 million as of June 2015, of which the number of pediatric patients affected is approximately 18 million (1). The statistical data issued by the Ministry of Health of China in 2015 showed that the total number of pediatric patients suffering from different types of blood diseases in China had reached over 4 million as of 2015 and increased steadily year by year (2). These numbers suggest that strengthening the diagnosis and treatment capabilities for blood diseases in children has become an important public health issue (3).

Clinical studies have shown that factors causing blood diseases in children are very complex, and can be mainly divided into environmental factors (living habits, diet, water and air pollution) and genetic factors (gene mutations, deletion and abnormal protein expression events) (4). The transcription factors of the GATA family bind to a [T/A(GATA)A/G] region in their target gene promoter regions to regulate the expression of specific genes, and directly regulate the expression of hematopoietic system-related mRNAs and proteins in the human body (5), as confirmed by genomic analyses (6). Additionally, studies that have shown that deletion and mutation of these sites leads to the decreased expression of disease-related genes necessary for normal hematopoietic stem cell functions (7). The GATA family includes multiple genes, such as GATA-1 and GATA-2, and a correlation study found that they likely play roles in many blood diseases (8).

In the present study, the correlation between GATA-3 gene products and blood diseases in children was investigated for the first time, in order to provide preliminary theoretical and experimental bases that may ultimately aid the diagnosis and treatment of blood diseases in children.

\section{Materials and methods}

General data. In the study, 35 pediatric patients diagnosed with hematological disorders treated in the Henan Red Cross Blood Center from January 2014 to June 2015 were enrolled and assigned to the observation group. The patients included 21 males aged 4-13 years (8.3 years on average), and 14 females aged 4-12 (8.2 on average). There were 7 cases of hematologic malignancies, 8 of acute lymphoblastic leukemia, 
6 of myeloproliferative disorder, 8 of acute non-lymphocytic leukemia, and 6 of thrombocytopenic purpura. At the same time, 32 healthy volunteers were assigned to the control group, which included 21 males with an average age of 7.8 years and 11 females with an average age of 8.3 years. Statistical analyses revealed that there were no significant differences in terms of age and sex between pediatric patients with blood disease and healthy controls $(\mathrm{P}>0.05)$, thus they were comparable.

The Ethics Committee of Henan Red Cross Blood Center approved the study and the patients and their families signed informed consent forms.

For sample acquisition, elbow venous blood $(5 \mathrm{ml})$ was drawn from patients and controls. The samples were centrifuged at $1000 \mathrm{x} \mathrm{g}$ for $10 \mathrm{~min}$ at $4^{\circ} \mathrm{C}$. Blood cells were taken, added into a solution of dimethylsulfoxide (DMSO) cryoprotectant and stored in cryovials in liquid nitrogen.

Quantitative polymerase chain reaction ( $q P C R$ ). For RNA extraction (9), approximately $0.3 \mathrm{~g}$ blood samples previously stored in liquid nitrogen were thawed on ice. Subsequently, $0.35 \mathrm{ml}$ RNA Plus (Thermo Fisher Scientific, Waltham, MA, USA) was added, and the sample was ground rapidly in a pre-cooled mortar, and immediately transferred into a $1.5 \mathrm{ml}$ RNase-free epoxy (EP) tube. The mortar was washed again with $0.15 \mathrm{ml}$ RNA Plus and the washing liquid was transferred into the same EP tube. Chloroform $(200 \mu \mathrm{l})$ was added, and the tube was rapidly vibrated for $15 \mathrm{sec}$ and placed at room temperature for $15 \mathrm{~min}$, followed by centrifugation at $1000 \mathrm{x} \mathrm{g}$ at $4^{\circ} \mathrm{C}$ for $15 \mathrm{~min}$. The supernatant was transferred into an RNase-free EP tube, and equivalent isopropanol was added, rapidly mixed and placed at room temperature for approximately $10 \mathrm{~min}$, followed by centrifugation at $1000 \times \mathrm{g}$ at $4^{\circ} \mathrm{C}$ for $10 \mathrm{~min}$. The supernatant was discarded, and $1000 \mu 175 \%$ ethanol was added and gently mixed, followed by centrifugation at $1000 \mathrm{x} \mathrm{g}$ at $4^{\circ} \mathrm{C}$ for $10 \mathrm{~min}$. The supernatant was discarded, and the remaining alcohol was removed as far as possible without touching the pellet. An appropriate amount of RNase-free water was added, the RNA mass was determined and an aliquot was used for quantitative PCR.

For RNA concentration and mass determination, RNA samples $(1 \mu \mathrm{l})$ were taken with a pipette and added into a micro-nucleic acid detector. Absorbance of samples at A260, A280 and A260/280 was determined using a micro-nucleic acid detector (Bio-Rad, Hercules, CA, USA). An A260/280 value of 1.8 and 2.0 indicated that RNA had no significant degradation and could be used for subsequent tests.

Reverse transcription- $P C R(R T-P C R)$. Reverse transcription and qPCR were performed as per the protocol of the kit by Life Scientific (Thermo Fisher Scientific). The fluorescence quantitative reaction system preparations [5 $\mu \mathrm{l}$ SYBR Premix Ex Taq II (2X), $0.5 \mu$ l PCR forward primer $(10 \mu \mathrm{M})$, $0.5 \mu \mathrm{l}$ PCR reverse primer $(10 \mu \mathrm{M}), 1 \mu \mathrm{l} \mathrm{cDNA}$ and $3 \mu \mathrm{l}$ $\mathrm{dH}_{2} \mathrm{O}$ ] were placed in a thermocycler (Applied Biosystems, Foster City, CA, USA). The primer sequences are shown in Table I. The results of qPCR were analyzed according to the $2^{-\Delta \Delta \mathrm{CT}}$ method.

Total protein extraction. The total protein was extracted from the experimental sample and stored in the refrigerator at $-80^{\circ} \mathrm{C}$.
Table I. Primers in quantitative PCR.

\begin{tabular}{ll}
\hline Primer & \multicolumn{1}{c}{ Sequence } \\
\hline GATA-3 & F: AGTCGTAGGCTAGCTAGGCTAC \\
& R: CGTAGTCGTAGCTAGTCGGATCG \\
GAPDH & F: TGACTTCAACAGCGACACCCA \\
& R: CACCCTGTTGCTGTAGCCAAA \\
\hline
\end{tabular}

F, forward; R, reverse.

Approximately $150 \mathrm{mg}$ of the experimental tissue sample were taken from the $-80^{\circ} \mathrm{C}$ refrigerator and ground in a mortar containing liquid nitrogen. The ground sample was collected in a $1.5 \mathrm{ml}$ EP tube, $300 \mu \mathrm{l}$ protein extract lysis buffer, and $10 \mu \mathrm{l}$ protease inhibitor was added and incubated in ice water for $30 \mathrm{~min}$, followed by centrifugation at $8,000 \mathrm{x} \mathrm{g}$ for $15 \mathrm{~min}$. The supernatants were collected for protein analysis.

ELISA. The total protein extracted from the blood samples in the experimental and control groups was used to determine the expression levels of GATA-3 via ELISA (10). The specific operation was carried out according to the instructions of the ELISA kit (Qiagen, Hilden, Germany). A standard curve was drawn according to the kit instructions, with the protein samples used diluted with Elution Buffer. The samples in the observation and control groups were diluted at 1:200 using sterilized PBS ( $\mathrm{pH}$ 7.2). Subsequently, $100 \mu 1$ samples to be tested were taken and added into 96-well plates, and $50 \mu 1$ detection solution was added into each well. After incubation at room temperature for $2 \mathrm{~h}, \mathrm{TMB}$ chromogenic substrate was added and the absorbance at $495 \mathrm{~nm}$ was measured in a multifunctional microplate reader (Bio-Rad). The protein expression and concentration of GATA-3 protein were calculated according to the standard curve.

Western blot analysis. Western blot analysis was used to detect the protein expression by a different means. Supernatant $(10 \mu \mathrm{l})$ was mixed with loading buffer, followed by SDS-PAGE using a protein electrophoresis apparatus (Beijing Liuyi Co., Ltd., Beijing, China) and conventional membrane transfer. After being sealed for $1 \mathrm{~h}$ at room temperature, the goat anti-human GATA-3 monoclonal antibody (dilution, 1:250; $4^{\circ} \mathrm{C}$ overnight) and rabbit anti-goat HRP-labeled secondary polyclonal antibody (dilution, 1:1,250, vibrated at room temperature for $1 \mathrm{~h}$ ) were added for incubation. After the membrane was washed 3 times, diaminobenzidine was used for color development (GAPDH antibody was directly visualized), followed by capturing of images using the Fluorchem 9900 imaging system. The integral optical density of each protein band was measured and the relative content of GATA-3 protein was calculated by normalizing the samples according to the GAPDH concentrations (11). The GATA-3 protein primary antibody was a goat anti-human monoclonal antibody purchased from Acris (cat. no. TA305795; Tiangen, Beijing, China); the rabbit anti-goat secondary polyclonal antibody (an HRP-labeled polyclonal antibody; cat. no. AP05548HR-N) 
A

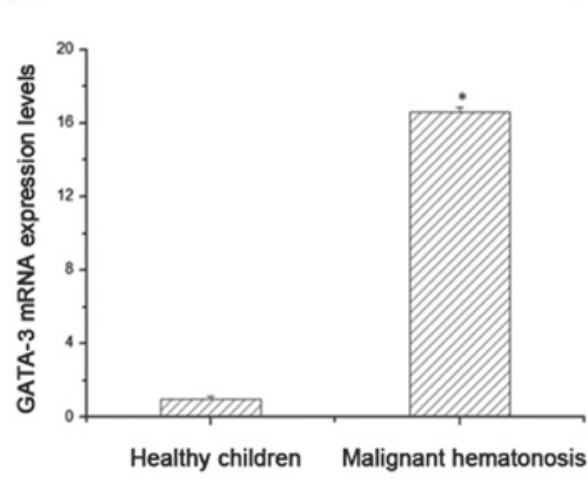

\section{C}

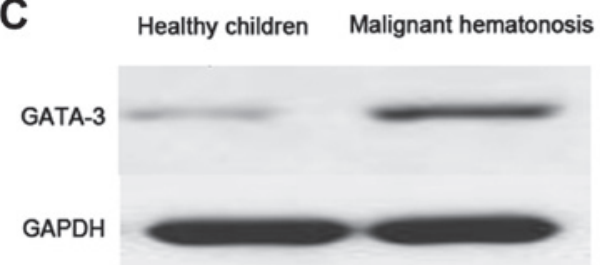

B

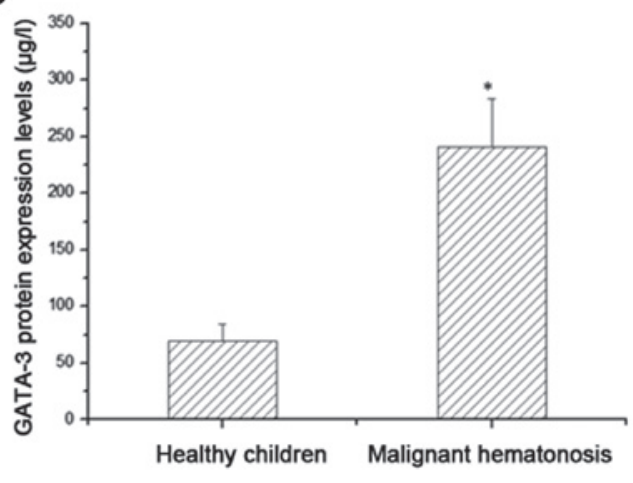

Figure 1. Differences in GATA-3 mRNA and protein expression levels in healthy children and pediatric patients with hematologic malignancies. (A) RT-PCR, (B) ELISA, and (C) western blot analysis. The GATA-3 mRNA and protein expression levels in healthy children are significantly lower than those in patients with hematologic malignancies, ${ }^{*} \mathrm{P}<0.05$.

and the glyceraldehyde-phosphate dehydrogenase (GAPDH) antibody (cat. no. TA302944) were purchased from Acris.

Statistical analysis. Experimental data were processed using SPSS 20.0 software (Applied Biosystems). The data were presented as mean \pm standard deviation. Student's t-test was used for comparison between groups. $\mathrm{P}<0.05$ was considered to indicate a statistically significant difference.

\section{Results}

Differences in mRNA and protein expression levels of GATA-3 between healthy children and pediatric patients with hematologic malignancies. In the present study, the blood samples from healthy children and pediatric patients with malignant hematonosis were used to extract total RNA and total protein samples. The mRNA expression levels of GATA-3 genes in the blood samples detected by qPCR showed the levels were significantly decreased in the healthy children $(\mathrm{P}<0.05)$ (Fig. 1A). Moreover, the protein expression levels of GATA-3 detected via ELISA showed the same trend with an average of $69.3 \pm 15.2 \mu \mathrm{g} / 1$ in the healthy control group and an average of $241.3 \pm 42.6 \mu \mathrm{g} / 1$ in the children affected with hematologic malignancies, which indicated a statistically significant difference $(\mathrm{P}<0.05)$ (Fig. 1B). Finally, the results of western blotting were consistent with those of ELISA (Fig. 1C). The average protein expression level of GATA-3 in patients with hematologic malignancies was significantly higher than that in healthy children.

Differences in $m R N A$ and protein expression levels of GATA-3 between healthy children and pediatric patients with acute lymphoblastic leukemia. The mRNA expression levels of GATA-3 in pediatric patients with acute lymphoblastic leukemia were significantly higher than those in healthy children $(\mathrm{P}<0.05)$ (Fig. 2A). The protein expression levels of GATA-3 in healthy children $(69.3 \pm 15.2 \mu \mathrm{g} / \mathrm{l})$ were significantly lower than those in patients with acute lymphoblastic leukemia $(196.3 \pm 21.6 \mu \mathrm{g} / \mathrm{l})$, and there was a significant difference between the two groups $(\mathrm{P}<0.05)$ (Fig. 2B). Moreover, results of the western blot analysis were consistent with those of ELISA (Fig. 2C).

Differences in mRNA and protein expression levels of GATA-3 between healthy children and pediatric patients with myeloproliferative disorder. As observed in Fig. 3A, the blood samples of healthy children contained mRNA expression levels of GATA-3 that were significantly lower than those in pediatric patients with myeloproliferative disorder $(\mathrm{P}<0.05)$. In addition, the protein expression levels of GATA-3 by ELISA in patients with myeloproliferative disorder $(284.2 \pm 45.1 \mu \mathrm{g} / \mathrm{l})$ were significantly higher than those in healthy children $(69.3 \pm 15.2 \mu \mathrm{g} / \mathrm{l})$, and there was a significant difference between the two groups $(\mathrm{P}<0.05)$ (Fig. 3B). The results of western blot analysis were consistent with those of ELISA and the protein expression level of GATA-3 in patients with myeloproliferative disorder was significantly higher than that in healthy children (Fig. 3C).

Differences in the $m R N A$ and protein expression levels of GATA-3 between healthy children and pediatric patients with acute non-lymphocytic leukemia. The mRNA expression levels of GATA-3 genes in the blood samples of healthy children are shown in Fig. 4A. The results show that, the average mRNA expression levels of GATA-3 in healthy children was significantly decreased than that in pediatric patients with acute non-lymphocytic leukemia $(\mathrm{P}<0.05)$. The average protein expression levels of GATA-3 detected via ELISA in patients with acute non-lymphocytic leukemia 
A

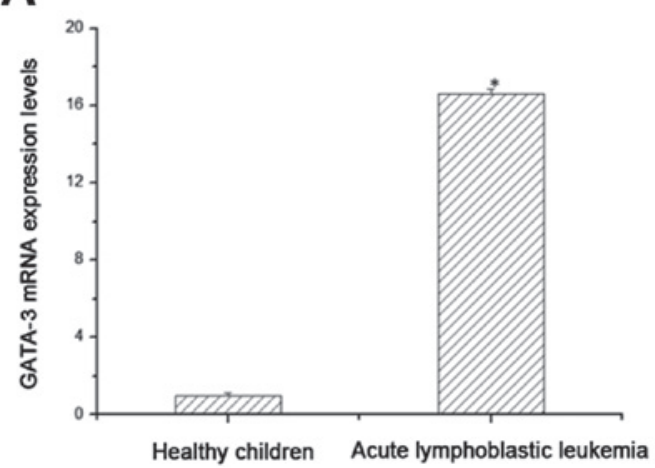

C
B

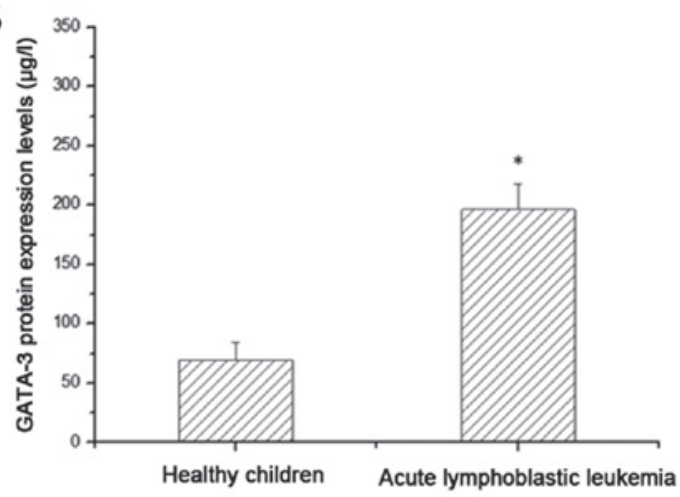

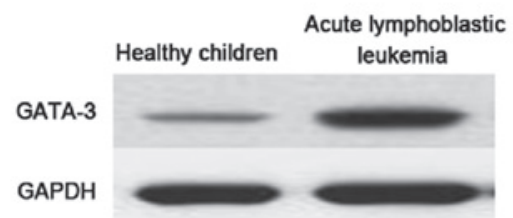

Figure 2. Differences in GATA-3 mRNA and protein expression levels in healthy children and pediatric patients with acute lymphoblastic leukemia. (A) RT-PCR, (B) ELISA, and (C) western blot analysis. The mRNA and protein expression levels of GATA-3 genes in healthy children are significantly lower than those in patients with acute lymphoblastic leukemia, ${ }^{\prime} \mathrm{P}<0.05$.

A

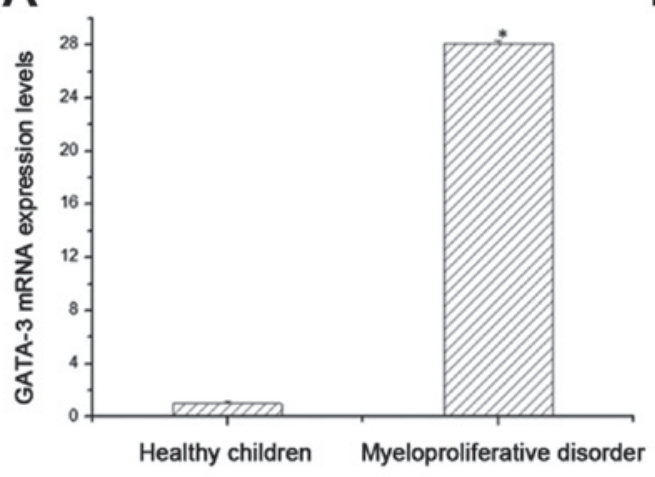

C

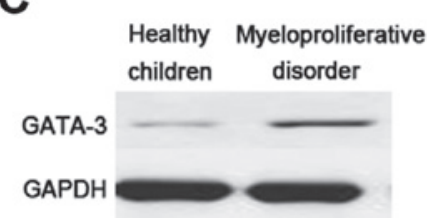

B

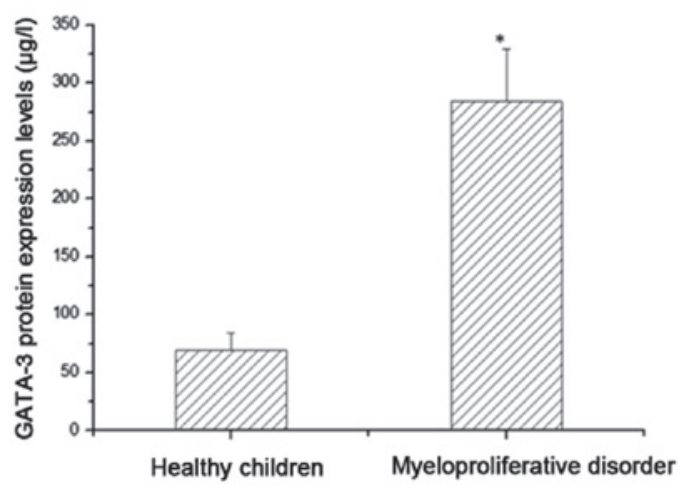

Figure 3. Differences in mRNA and protein expression levels of GATA-3 genes in healthy children and child patients with myeloproliferative disorder. (A) RT-PCR, (B) ELISA, and (C) western blot analysis. The GATA-3 mRNA and protein expression levels in healthy children are significantly lower than those in patients with myeloproliferative disorder, ${ }^{*} \mathrm{P}<0.05$.

$(269.3 \pm 31.4 \mu \mathrm{g} / \mathrm{l})$ was significantly higher than that in healthy children $(69.3 \pm 15.2 \mu \mathrm{g} / \mathrm{l})$, and there was a significant difference between the two groups $(\mathrm{P}<0.05)$. The results of western blot analysis were consistent with those of ELISA as is evident in Fig. 4C. The protein expression levels of GATA-3 in patients with acute non-lymphocytic leukemia were significantly higher than those in healthy children.

Differences in $M R N A$ and protein expression levels of GATA-3 between healthy children and pediatric patients with thrombocytopenic purpura. The results shown in Fig. 5A show the average mRNA expression level of GATA-3 in healthy children was significantly lower than that in pediatric patients with thrombocytopenic purpura $(\mathrm{P}<0.05)$. At the same time, the protein expression levels of GATA-3 obtained via ELISA, show significantly higher levels in patients with thrombocytopenic purpura $(272.1 \pm 39.1 \mu \mathrm{g} / \mathrm{l})$ than in healthy controls $(69.3 \pm 15.2 \mu \mathrm{g} / \mathrm{l})$, and there was a significant difference between the two groups $(\mathrm{P}<0.05)$. The results of western blot analysis were consistent with those of ELISA. The protein 
A

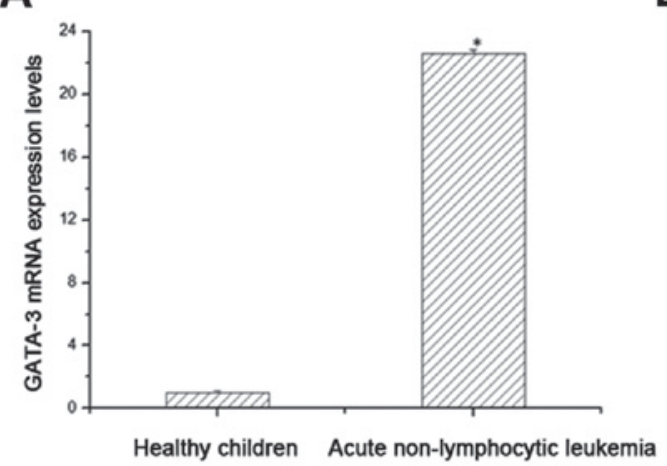

C

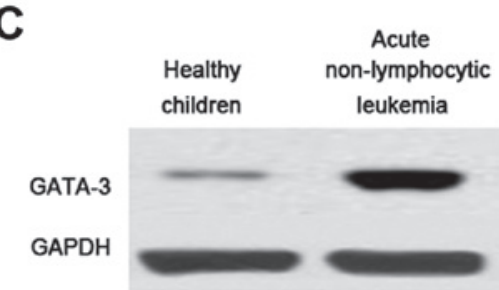

B

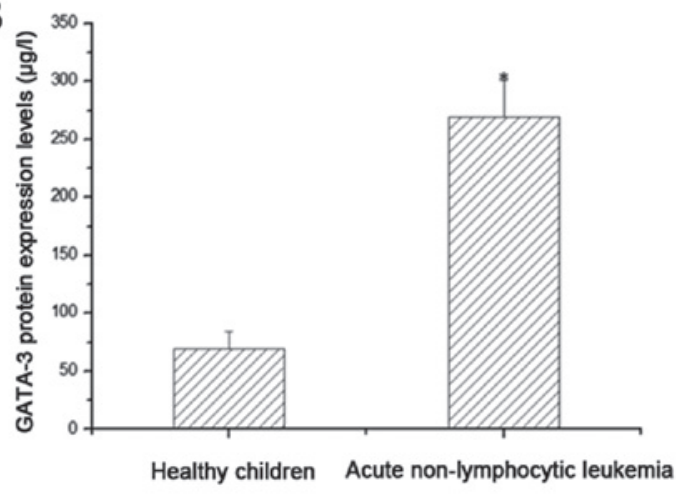

Figure 4. Differences in GATA-3 mRNA and protein expression levels in healthy children and pediatric patients with acute non-lymphocytic leukemia. (A) RT-PCR, (B) ELISA, and (C) western blot analysis. The mRNA and protein expression levels of GATA-3 genes in healthy children are significantly lower than those in patients with acute non-lymphocytic leukemia, ${ }^{*} \mathrm{P}<0.05$.

A

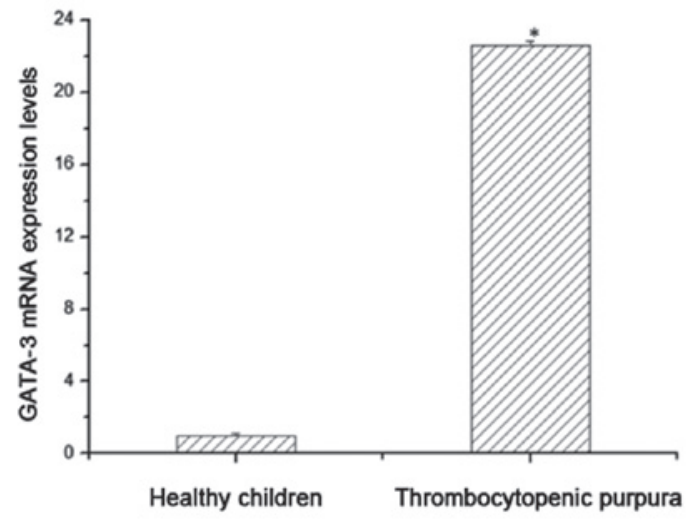

B

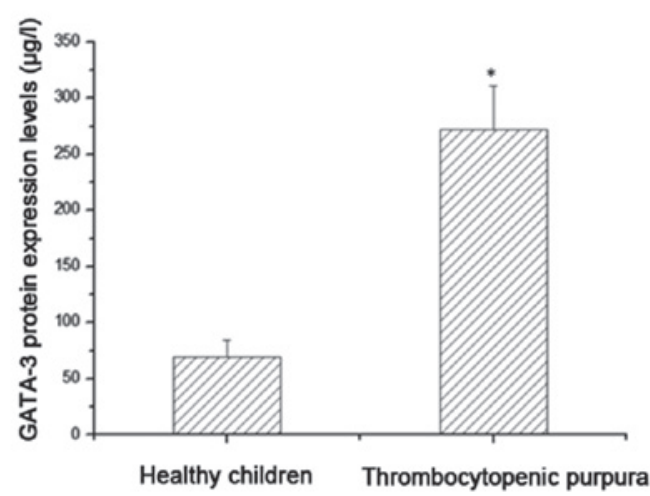

C

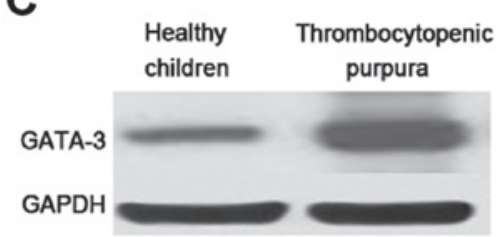

Figure 5. Differences in GATA-3 mRNA and protein expression levels in healthy children and children with thrombocytopenic purpura. (A) RT-PCR, (B) ELISA, and (C) western blot analysis. The mRNA and protein expression levels of GATA-3 genes in healthy children are significantly lower than those in patients with thrombocytopenic purpura, ${ }^{*} \mathrm{P}<0.05$.

expression levels of GATA-3 in patients with thrombocytopenic purpura were significantly higher than those in healthy children (Fig. 5B and C).

Changes in the protein expression levels of GATA-3 in pediatric patients with different blood diseases at different disease progression times. In the study, the protein expression levels of GATA-3 in pediatric patients with blood diseases were detected via ELISA on repeated occasions to determine variations over the course of the disease. The results are shown in Fig. 6. It can be seen that the protein expression levels of GATA-3 in patients with hematologic malignancies, acute lymphoblastic leukemia, myeloproliferative disorder, acute non-lymphocytic leukemia, and thrombocytopenic purpura 


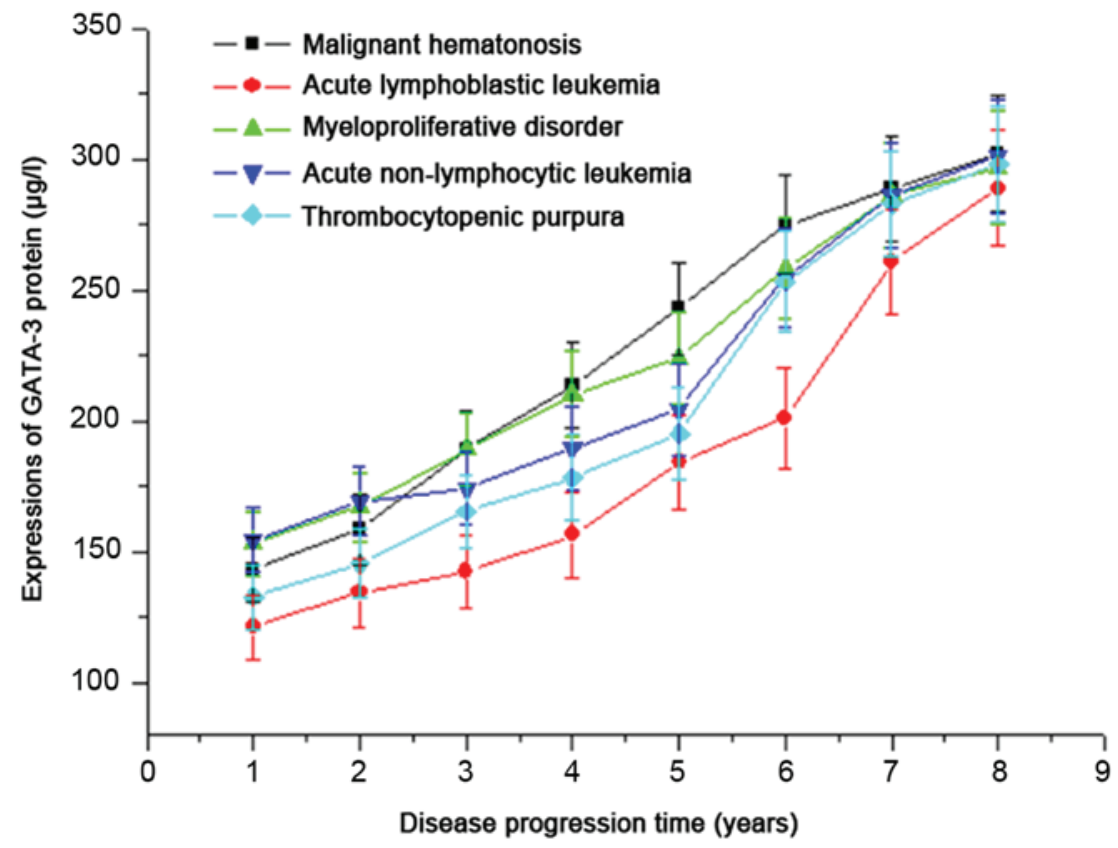

Figure 6. Changes across time in the protein expression levels of GATA-3 in pediatric patients with different blood diseases.

increased gradually with time, indicating that the protein expression level of GATA-3 is positively associated with these hematologic disorders in children.

\section{Discussion}

In recent years, the incidence of hematologic disorders in children has been on the increase worldwide. Thus, conditions have become important public health issues requiring improvements in diagnostic and therapeutic approaches (12). Blood diseases are hematopoietic system dysfunctions of diverse etiology (13), whose main clinical symptoms include anemia, or bleeding, and fever. Research on the pathogenesis of hematologic disorders suggests that multiple factors play a role in the pathogenesis of the different disorders, including chemical factors (carcinogenic drugs), physical factors (radiation), biological factors (invasion by pathogenic bacteria), and genetic immune deficiencies (14). It is thought that external factors, such as radiation and/or chemical substances, cause immune system defects in the body, leading to hematopoietic system dysfunction, which is usually associated with resulting genetic mutations (15).

Transcription factors play important regulatory roles on the gene expression of various systems (16). Transcription factors of the GATA family play important roles in the human hematopoietic system (17). The GATA-3 transcription factor is a zinc finger protein in the human body that is mainly involved in the development, maturity, proliferation and differentiation of T cells and other immune cells (18). For example, GATA-3 can specifically regulate Th2 cell differentiation through regulation of the formation of Th2 and Th1 (19). On this basis, GATA-3 is considered to play an important role in various types of leukemia. The GATA-3 gene products can participate in the $\mathrm{NF}-\kappa \mathrm{B}$ signaling pathway, and the $\mathrm{NF}-\kappa \mathrm{B}$ signaling pathway, in turn, acts as a tumor and cancer signal in other transduction pathways in the body. Furthermore, previous findings showed that blocking the $\mathrm{NF}-\kappa \mathrm{B}$ signaling pathway can significantly reduce the mRNA expression level of GATA-3, although the specific mechanism remains to be elucidated (20).

To the best of our knowledge, in this study, the correlation between GATA-3 gene products and hematologic diseases in children was investigated for the first time. The results showed that the mRNA and protein expression levels of GATA-3 in patients with hematologic malignancies, acute lymphoblastic leukemia, myeloproliferative disorder, acute non-lymphocytic leukemia, and thrombocytopenic purpura were significantly higher than those in healthy children, and the differences were statistically significant. Furthermore, the levels of GATA-3 mRNA and protein increased gradually in the affected pediatric patients with the progression of disease. We suggest that levels of GATA-3 products be determined in children to aid diagnosis and treatment assessment of hematologic disorders.

\section{References}

1. Maria Murga Penas E, Schilling G, Behrmann P, Klokow M, Vettorazzi E, Bokemeyer C and Dierlamm J: Comprehensive cytogenetic and molecular cytogenetic analysis of 44 Burkitt lymphoma cell lines: Secondary chromosomal changes characterization, karyotypic evolution, and comparison with primary samples. Genes Chromosomes Cancer 53: 497-515, 2014.

2. Abla $\mathrm{O}$ and Ribeiro RC: How I treat children and adolescents with acute promyelocytic leukaemia. Br J Haematol 164: 24-38, 2014.

3. Silva AG, Maschietto M, Vidal DO, Peliçario LM, Velloso ED, Lopes LF, Krepischi AC and Rosenberg C: Array-CGH as an adjuvant tool in cytogenetic diagnosis of pediatric MDS and JMML. Med Oncol 30: 734, 2013.

4. Hoyos M, Nomdedeu JF, Esteve J, Duarte R, Ribera JM, Llorente A, Escoda L, Bueno J, Tormo M, Gallardo D, et al: Core binding factor acute myeloid leukemia: The impact of age, leukocyte count, molecular findings, and minimal residual disease. Eur J Haematol 91: 209-218, 2013.

5. Zhang R, Yang JY, Sun HQ, Jia H, Liao J, Shi YJ and Li G: Comparison of minimal residual disease (MRD) monitoring by WT1 quantification between childhood acute myeloid leukemia and acute lymphoblastic leukemia. Eur Rev Med Pharmacol Sci 19: 2679-2688, 2015. 
6. Imamura T, Iwamoto S, Kanai R, Shimada A, Terui K, Osugi Y, Kobayashi R, Tawa A, Kosaka Y, Kato K, et al; Japan Association of Childhood Leukaemia Study: Outcome in 146 patients with paediatric acute myeloid leukaemia treated according to the AML99 protocol in the period 2003-06 from the Japan Association of Childhood Leukaemia Study. Br J Haematol 159: 204-210, 2012

7. Gao C, Zhao XX, Li WJ, Cui L, Zhao W, Liu SG, Yue ZX, Jiao Y, Wu MY and Li ZG: Clinical features, early treatment responses, and outcomes of pediatric acute lymphoblastic leukemia in China with or without specific fusion transcripts: A single institutional study of 1,004 patients. Am J Hematol 87: 1022-1027, 2012.

8. Braoudaki M and Tzortzatou-Stathopoulou F: Clinical cytogenetics in pediatric acute leukemia: An update. Clin Lymphoma Myeloma Leuk 12: 230-237, 2012.

9. Park BW, Kang DH, Kang EJ, Byun JH, Lee JS, Maeng GH and Rho GJ: Peripheral nerve regeneration using autologous porcine skin-derived mesenchymal stem cells. J Tissue Eng Regen Med 6: 113-124, 2012

10. Kanematsu D, Shofuda T, Yamamoto A, Ban C, Ueda T, Yamasaki $\mathrm{M}$ and Kanemura Y: Isolation and cellular properties of mesenchymal cells derived from the decidua of human term placenta. Differentiation 82: 77-88, 2011

11. Tang Y, Wei Y, He W, Wang Y, Zhong J and Qin C: GATA transcription factors in vertebrates: Evolutionary, structural and functional interplay. Mol Genet Genomics 289: 203-214, 2014

12. Gao Y, Chen J, Li K, Wu T, Huang B, Liu W, Kou X, Zhang Y, Huang H, Jiang Y, et al: Replacement of Oct4 by Tet1 during iPSC induction reveals an important role of DNA methylation and hydroxymethylation in reprogramming. Cell Stem Cell 12: 453-469, 2013.

13. Ragbourne SC and Crook MA: Metabolic syndrome in long-term survivors of hematopoietic stem-cell transplantation. Clin Lymphoma Myeloma Leuk 17: 340-346, 2017.
14. Shu J, Wu C, Wu Y, Li Z, Shao S, Zhao W, Tang X, Yang H, Shen L, Zuo X, et al: Induction of pluripotency in mouse somatic cells with lineage specifiers. Cell 153: 963-975, 2013.

15. Buganim Y, Faddah DA, Cheng AW, Itskovich E, Markoulaki S, Ganz K, Klemm SL, van Oudenaarden A and Jaenisch R: Single-cell expression analyses during cellular reprogramming reveal an early stochastic and a late hierarchic phase. Cell 150: 1209-1222, 2012.

16. Bertucci F, Finetti P and Birnbaum D: Basal breast cancer: A complex and deadly molecular subtype. Curr Mol Med 12: 96-110, 2012

17. Gros C, Fahy J, Halby L, Dufau I, Erdmann A, Gregoire JM, Ausseil F, Vispé S and Arimondo PB: DNA methylation inhibitors in cancer: Recent and future approaches. Biochimie 94: 2280-2296, 2012.

18. Xu LH, Guo Y, Cen JN, Yan WY, He HL, Niu YN, Lin YX, Chen CS and Hu SY: Overexpressed miR-155 is associated with initial presentation and poor outcome in Chinese pediatric acute myeloid leukemia. Eur Rev Med Pharmacol Sci 19: 4841-4850, 2015.

19. Reikvam H, Hatfield KJ, Kittang AO, Hovland R and Bruserud $\varnothing$ : Acute myeloid leukemia with the $\mathrm{t}(8 ; 21)$ translocation: Clinical consequences and biological implications. J Biomed Biotechnol 2011: 104631, 2011.

20. Campbell K, Whissell G, Franch-Marro X, Batlle E and Casanova J: Specific GATA factors act as conserved inducers of an endodermal-EMT. Dev Cell 21: 1051-1061, 2011. 